\title{
JOURNAL OF THE ROYAL SOCIETY OF MEDICINE
}

June 2005 Volume 98 Number 6 ISSN 0141-0768

\section{An action plan for tuberculosis in England}

Since the mid-1980s the world has seen a steady increase in tuberculosis of about 1\% a year, but in the UK the increase has been nearer $2 \%$ a year. ${ }^{1,2}$ In the Americas and most of Western (though not Eastern) Europe, tuberculosis case rates are falling; sub-Saharan Africa is seeing huge rises, because of the immunocompromising effects of HIV. In the UK the increase in cases has effectively been confined to London, where a doubling of numbers in the past decade is attributable to immigration from countries with a high prevalence. Particularly affected is the London Borough of Newham, where the incidence now exceeds 80/100000 per year. Poor housing and a deficient infrastructure make matters worse.

In October 2004, the Department of Health launched a report with the bold title Stopping Tuberculosis in England. ${ }^{3}$ The Chief Medical Officer's action plan centres on ten broad principles - increased awareness, strong commitment and leadership, a high quality of service, excellence of clinical care, well organized and well coordinated patient services, first-class laboratory services, highly effective disease control at population level, an expert workforce, leading edge research, and international partnership. Nobody could quarrel with these, but how is this plan to be implemented? On 9 March 2005 the RSM held a meeting to debate the action plan and some key points are recorded here.

As usual, resources loomed large. The Government's report admiringly uses the word 'can-do' to describe the strategy adopted in New York in the early 1990s, when an increase in tuberculosis similar to that in London was successfully reversed. What it omits to mention is the considerable expense of the New York programme; each case of tuberculosis prevented cost around $\$ 10000 .{ }^{4}$ One plus-point for the UK, in dealing with the epidemic, is the high quality of the Mycobacterial Laboratory Reference system. New molecular techniques (such as the polymerase chain reaction and gene probe identification) have brought the times for identification of species and drug resistance down to a few days. Unfortunately, there has been little improvement in sensitivity; so we still find ourselves treating $20-40 \%$ of patients empirically, without confirmation of the diagnosis. One very promising development for early diagnosis is a blood test for T cells specific for antigens of Mycobacterium tuberculosis. This is more accurate than the tuberculin skin test, now a hundred years old, and should be particularly useful for detection of latent infection. ${ }^{5} \mathrm{On}$ 'excellence of clinical care', a difficulty in England is the patchiness of tuberculosis, so that some clinicians gain much experience and others very little. Practice and control have until now been overseen by the British Thoracic Society's Tuberculosis Committee, with occasional pronouncements on best practice. ${ }^{6,7}$ From next February, everyone who manages tuberculosis will need to consult guidelines from the National Institute for Clinical Excellence (NICE). Meanwhile, some promising new treatment agents are entering phase 2 trials $^{8}{ }^{8}$ and, on the vaccine front, the leading contender is a vaccinia-based mycobacterial antigen that boosts immunity to BCG. ${ }^{9}$

Two important areas of controversy were highlighted at the RSM meeting. Contrary to popular opinion (and to much political opinion), no good argument can be made for routine screening of new immigrants for active disease. Where screening is in operation, it identifies only one person with active tuberculosis for every thousand immigrants examined, and few of these individuals are infectious. Most immigrants who present with tuberculosis acquire their symptoms and signs between one and five years after arrival, so the disease is unlikely to be picked up on entry. Moreover, the numbers of specialist nurses, whose principal role is to provide support for patients taking medication and identifying contacts for tracing, are insufficient to provide a comprehensive immigrant screening service. There is a better case for screening of young immigrants who might benefit from preventive therapy. Also, some uninfected children should receive BCG. This is not true of UK children in general: the rates of tuberculosis in white teenagers and young adults are now so low that about 4500 routine vaccinations at the age of thirteen are being given to prevent a single case; the existing vaccination programme is far from being cost-effective. ${ }^{10}$

No new monies, we are told, are to be made available for implementing the Government's action plan, so can the old monies be applied more effectively? A recent outbreak of isoniazid-resistant tuberculosis in North London might have been curtailed if resources had been better targeted. ${ }^{11,12}$ Discontinuation of the school BCG programme could release funds for employment of more specialist nurses to provide patient support and directly observed therapy. Screening of immigrants, where 
necessary, might best be done in primary care. Routine screening of symptom-free adult immigrants could be suspended, with redirection of resources to prevention of disease in the young.

Acknowledgments Speakers at the conference were John Watson, John Hayward, Francis Drobniewski, Peter Ormerod, Richard Coker, John Moore-Gillon, Susan Jamieson, Noel Snell, Jane Leese and John Scadding, and the chairs were Catherine Quigly, Ian Campbell and Janet Darbyshire. The full presentations can be found on the RSM and TB Alert websites, [www.rsm.ac.uk] and [www.tbalert.org]

\section{Peter Davies}

Cardiothoracic Centre, Thomas Drive,

Liverpool L14 3PE, UK

E-mail: Peter.davies@ctc.nhs.uk

\section{REFERENCES}

1 [www.who.int/mediacentre/factsheets/fs104/en] Accessed 11 March 2005
2 [www.hpa.org.uk/infections/topicas_az/tb/menu.htm] Accessed 11 March 2005

3 Donaldson L. Stopping Tuberculosis in England. London: Department of Health, 2004

4 Frieden TR, Fujiwara PI, Washko R, Hamburg MA. Tuberculosis in New York City - turning the tide. N Engl J Med 1995;333:229-33

5 Ewer K, Deeks J, Alvarez L, et al. Comparison of T-cell-based assay with tuberculin skin test for diagnosis of Mycobacterium tuberculosis infection in a school tuberculosis outbreak. Lancet 2003;361:1168-73

6 Joint Tuberculosis Committee of the British Thoracic Society. Chemotherapy and management of tuberculosis in the United Kingdom: recommendations 1998. Thorax 1998;53:536-48

7 Joint Tuberculosis Committee of the British Thoracic Society. Control and prevention of tuberculosis in the United Kingdom: code of practice 2000. Thorax 2000;55;887-901

8 Rubin EJ. Towards a new therapy for tuberculosis. N Engl J Med 2005;352:933-4

9 McShane H, Pathan AA, Sander CR, et al. Recombinant modified vaccinia virus Ankara expressing antigen 85A boosts BCG-primed and naturally acquired antimycobacterial immunity in humans. Nature Med 2004; 10:1240

10 Davies P. BCG: is it time to phase it out? Airways J 2003;11:184-6

11 Ruddy MC, Davies AP, Yates MD, et al. Outbreak of isoniazid resistant tuberculosis in north London. Thorax 2004;59:279-85

12 Davies PDO. Molecular epidemiology unmasks the tubercle bacillus: new techniques reveal new aspects of virulence. Thorax 2004;59:273-4 